\title{
O papel da consciência morfossintática na aquisição e no aperfeiçoamento da leitura e da escrita
}

\section{The role of morphosyntactic awareness in the acquisition and in reading and writing improvement}

\author{
Sandra Regina Kirchner Guimarães ${ }^{1}$ \\ Fraulein Vidigal de Paula ${ }^{2}$
}

\begin{abstract}
RESUMO
Nos últimos decênios, diversos estudos verificaram que as habilidades metalinguísticas têm papel essencial na aquisição da linguagem escrita e revelam-se associadas à maior ou menor eficácia dessa aquisição. Entretanto, enquanto a relação entre metafonologia e aprendizagem da leitura e da escrita está bem documentada, estudos sobre a relação entre a consciência morfossintática e aprendizagem da escrita são ainda pouco numerosos. Considera-se que a partir do estágio alfabético de aquisição da escrita, o aprendiz precisa enfrentar diferentes questões relativas tanto a leitura (decodificação e compreensão) como a escrita (ortografia), diante das quais se amplia a importância da consciência morfossintática, dado que mesmo nos sistemas de escrita alfabéticos não se verifica uma correspondência biunívoca e recíproca entre letra e som. Neste artigo é apresentada uma série de estudos conduzidos em vários idiomas, com destaque para os estudos conduzidos no português brasileiro, que tiveram como objetivo verificar a relação entre a consciência morfossintática e a aquisição e o aperfeiçoamento da linguagem escrita.

Palavras-chave: consciência morfossintática; desempenho em leitura e escrita; desenvolvimento metalinguístico.
\end{abstract}

1 Doutora em Psicologia pela Universidade de São Paulo. Professora da Universidade Federal do Paraná - Brasil, srkguimaraes@uol.com.br

2 Doutora em Psicologia pela Universidade de São Paulo. Professora da Universidade de São Paulo - Brasil, frauleindepaula@gmail.com 


\begin{abstract}
In the last decades, several studies verified that metalinguistic skills have an essential role in written language acquisition and have proven to be linked to a lesser or greater success in this acquisition. However, while the relation between metaphonology and reading and writing learning is well documented, studies on the relationships between morphosyntactic consciousness and writing learning are relatively scarce. It is now a consensus that since from the alphabetic stage of writing learning the apprentice needs to solve several different problems in reading (decoding and comprehension) and in writing (orthography) which increase the importance of morphosyntactic consciousness, given that even in the alphabetic writing systems there is not a biunivocal correspondence between letters and sounds. In this paper we present a series of studies conducted in several languages with emphasis in the studies conducted in Brazilian Portuguese that aimed to verify the relation between mophosyntactic consciousness and written language acquisition and improvement.
\end{abstract}

Keywords: morphosyntactic awareness; reading and writing performance; metalinguistic development.

\title{
Introdução
}

$\mathrm{O}$ ato de ler e escrever requer, por parte de quem o faz, o domínio de diversas habilidades linguístico-cognitivas relativas a um sistema de escrita. Além disso, várias evidências empíricas têm demonstrado que as habilidades metalinguísticas - que envolvem a capacidade de pensar e manipular conscientemente o conhecimento linguístico - são também primordiais para a aprendizagem formal da escrita na escola. Destaca-se que nas últimas décadas multiplicaramse as pesquisas que têm investigado o papel das habilidades (meta)linguísticas na aquisição da linguagem escrita e como elas se relacionam com a maior ou menor eficácia nessa aquisição.

Nesse sentido, um grande número de estudos tem evidenciado uma relação estreita entre a aquisição do sistema de escrita e a consciência dos constituintes fonológicos das palavras, a chamada "consciência fonológica" (BARRERA; MALUF, 2003; BRADLEY; BRYANT, 1983; CAPOVILLA; CAPOVILLA, 2000; CARDOSO-MARTINS, 1995; GUIMARÃES, 2003; PLAZA; COHEN, 2003, 2004; REGO; BRYANT, 1993; ROAZZI; DOWKER, 1989; TUNMER, 1990). Esses autores demonstram que a consciência fonológica é necessária para a aprendizagem da linguagem escrita nas línguas alfabéticas como o francês, inglês ou o português, pois seus sistemas de escrita envolvem a análise das 
palavras em unidades fonológicas mínimas, os fonemas, os quais são representados pelas letras. No entanto, não se verifica nesses sistemas de escrita uma correspondência biunívoca e recíproca entre letra e som.

Na realidade, a escrita representa sons, mas também significados de uma língua. Portanto, combina dois princípios indispensáveis para sua existência e funcionamento, como salientam Marec-Breton e Gombert (2004). O primeiro é fonográfico e diz respeito à relação entre unidades sonoras ou fonemas (/f/l/o/r/) e unidades gráficas ou grafemas (f-l-o-r). O segundo princípio é semiográfico e permite que unidades gráficas (flor) correspondam também a um significado (flor = órgão da reprodução sexuada das plantas superiores). Os morfemas são os menores signos linguísticos que encerram um significado: se a palavra "flor" for reduzida a "fl" o significado desaparece, pois em português /fl/ não significa nada. Uma palavra pode ser formada de um único morfema (palavra simples, tal como "flor") ou mais morfemas (palavra complexa, tal como, "flores" que significa mais de uma flor).

Os morfemas em português cumprem várias funções na palavra, pois podem constituir sua base essencial, ampliar e modificar seu sentido ou sua classe gramatical, flexioná-la e colocá-la em um contexto sintático, ou mesmo ligar termos em uma sentença. Para utilizar habilmente este conhecimento, é preciso examinar algumas particularidades da morfologia e das habilidades (meta)linguísticas relativas à morfologia, necessárias ao usuário da língua.

Tradicionalmente, os linguístas reconhecem duas grandes classes de morfemas no que diz respeito a sua posição na palavra: as raízes e os afixos. Quanto à função, a raiz, ou morfema lexical, constitui o núcleo mínimo de uma construção morfológica, portador de uma significação básica e comum a várias palavras de um mesmo grupo lexical. Assim, em livro, livrinho, livreiro, livraria, e livresco, a raiz é livr-. Os afixos (compreendidos pelos morfemas sem autonomia morfossintática) podem ser de dois tipos: prefixos, quando adicionados antes da raiz, ou sufixos, quando adicionados depois da raiz (LAROCA, 2005; SILVA; KOCH, 2005). Em relação à função na palavra, os afixos podem representar um papel derivacional ou um papel flexional.

Os morfemas derivacionais podem ser encontrados antes (prefixo) ou depois do morfema lexical (sufixo), alterando seu sentido ou classe gramatical inicial e permitindo a geração ou formação de novas palavras na língua. Por exemplo, nos pares:fazer/refazer, ou fazer/desfazer, o sentido inicial da palavra "fazer" foi alterado pelos prefixos re- ou des-, gerando palavras com significados diferentes na língua. O morfema derivacional pode modificar, além do sentido, a classe gramatical da palavra, por exemplo, no par: nadar/nadador, a palavra "nadador" se relaciona por derivação com a palavra "nadar", pelo acréscimo do sufixo derivacional -ador. Como as derivações interferem na estrutura das palavras, pode haver uma instabi- 
lidade semântica (por exemplo: correr/corredor, em que corredor pode significar "aquele que corre", mas também "lugar de passagem"). Assim, pode-se dizer que os morfemas derivacionais desempenham uma função semântico-lexical.

Os morfemas flexionais são sempre sufixos, ou seja, só podem aparecer no final da palavra. Estes alteram o morfema lexical, ou raiz para que este se adapte ao contexto sintático da palavra. Podem ser acrescentados a substantivos e adjetivos para flexionar o gênero (masculino e feminino, como em menin-o e menin-a) e número (singular e plural, como em menino e menino-s), mas também a verbos, para flexioná-lo em termos de modo (a atitude de certeza, incerteza, impossibilidade, solicitação etc.) e tempo (em que ocorre a ação verbal), além de número (singular e plural) e pessoa (o sujeito do enunciado da ação verbal). (SILVA; KOCH, 2005). Pode-se dizer que a flexão e os morfemas flexionais têm caráter morfossintático, pois cumprem uma exigência de concordância nominal ou verbal, de acordo com a necessidade imposta pela frase. Por exemplo, na frase: Nós estivemos em São Paulo no mês passado, identifica-se uma clara relação entre nós e estivemos (concordância na primeira pessoa do plural). Além disso, destaca-se que enquanto nas derivações as palavras podem ter uma extensão no significado, as flexões mantêm uma estabilidade semântica.

$\mathrm{Na}$ realidade, considerando as interrelações entre o nível morfológico e sintático, vários linguístas referem-se à morfossintaxe - apesar da discussão em torno da autonomia da morfologia como uma disciplina distinta da sintaxe ${ }^{3}$. Carone (2006) defende que, como um recurso didático, esses dois aspectos da organização da língua (morfologia e sintaxe) podem ser conceituados e estudados separadamente, embora grandes semelhanças estruturais os aproximem, e em alguns momentos chegam a se imbricar, se entrelaçar. Para sustentar seu ponto de vista, a autora destaca a concordância (tanto nominal quanto verbal) como um aspecto que aproxima e confunde morfologia e sintaxe. Ela explica a concordância como um fato morfológico, na medida em que é um fenômeno que ocorre no corpo das palavras que se flexionam; mas é também um fato sintático, pois só ocorre entre palavras que desempenham uma função quando se relacionam sintaticamente. A autora conclui que "a concordância é a manifestação mórfica de uma relação sintática. " (p.100)

Cabe salientar ainda que, um signo linguístico pode ter extensão variável, desde a menor delas, que é justamente o morfema, até a palavra, a frase, o texto

3 Laroca (2005) sintetiza argumentos que expressam essa discussão: por um lado, apresenta a declaração de Saussure (1975, apud LAROCA, 2005) "a morfologia não tem objeto real e autônomo" e, por outro lado, apresenta a refutação de Mattoso Câmera (1972, apud LAROCA, 2005), que tomando como exemplo a forma pronominal ele, afirma o seu valor morfológico, ou seja, trata-se "de um pronome masculino, e não feminino; singular e não plural; da terceira pessoa gramatical, e não da primeira ou segunda" (p.13). 
etc. Portanto, entre as habilidades metalinguísticas é importante considerar não apenas a habilidade metafonológica, mas também a metamorfológica, a metassintática e a metatextual (GOMBERT, 1992; MOTA, 2009).

De acordo com Carlisle (2000), a consciência morfológica diz respeito à habilidade para refletir e manipular intencionalmente a estrutura morfológica da língua. Em outras palavras, é a habilidade de fazer uso explícito dos processos de formação, flexão e classificação de palavras em uma língua. Por sua vez, a consciência sintática se refere ao controle intencional e emprego consciente da sintaxe da língua (GOMBERT, 1992). Mais especificamente, diz respeito à habilidade de fazer uso explícito dos processos formais relativos à organização das palavras para produção e compreensão de frases.

Dado que o sistema ortográfico representa simultaneamente os níveis fonológico e morfossintáticos, sugere-se que a aprendizagem da leitura e da escrita é influenciada tanto pela consciência fonológica quanto pela consciência morfossintática - a qual possibilita a focalização das palavras como categorias gramaticais e a sua adequada posição na construção das frases, aumentando a capacidade de identificação e produção da linguagem escrita. Por exemplo, imaginandose uma frase no pretérito perfeito, terceira pessoa do singular: muitos falantes do português brasileiro dizem /falô/ para "falou", /dançô/ para "dançou" etc., não pronunciando o "u" final. Contudo, se tiverem capacidade para refletir e manipular mentalmente a estrutura morfossintática, eles poderão utilizá-la para solucionar possíveis dificuldades e obter maior domínio da escrita ortográfica. Entretanto, é fundamental não perder de vista que a consciência morfossintática é um constructo multifacetado, ou seja, uma habilidade composta por múltiplas dimensões (ROAZZI; ASFORA; QUEIROGA, no prelo).

Nessa perspectiva, nas seções seguintes serão examinados estudos que têm investigado as relações entre a consciência morfossintática e outras habilidades cognitivas. Pretende-se analisar estudos realizados por pesquisadores estrangeiros e brasileiros com o objetivo de identificar evidências empíricas sobre o papel da consciência morfossintática na aquisição e no aperfeiçoamento da leitura e da escrita.

\section{Consciência morfossintática e a aprendizagem da leitura e da escrita: estudos realizados no exterior}

De acordo com Tunmer, Herriman e Nesdale (1988), na literatura se encontram três explicações diferentes a respeito do desenvolvimento das habili- 
dades metalinguísticas na criança. A primeira sugere que as habilidades metalinguísticas surgem concomitantemente à linguagem oral e desenvolvem-se a partir da utilização de mecanismos de detecção de erros empregados pelos indivíduos no monitoramento da sua fala. A segunda propõe que as habilidades metalinguísticas teriam um desenvolvimento independente e posterior em relação às habilidades linguísticas básicas de caráter comunicativo, estando relacionadas a mudanças mais gerais no desenvolvimento cognitivo que ocorreriam por volta dos sete anos de idade e seriam responsáveis pelo controle consciente sobre o processamento de informações. A terceira defende que as habilidades metalinguísticas seriam o resultado do processo de aprendizagem da linguagem escrita possibilitado pela escolarização formal.

Para buscar evidências que sustentem essas diferentes explicações muitas pesquisa têm sido conduzidas, sendo que a maioria delas focaliza a relação, exaustivamente documentada, entre metafonologia e aprendizagem da linguagem escrita. Por isso, acredita-se ser importante revisar os estudos que investigaram também, ou exclusivamente, outras habilidades metalinguísticas - no caso dos estudos abordados neste artigo, a consciência morfossintática.

Inicialmente serão apresentados os trabalhos que focalizam de forma prioritária as habilidades morfológicas, depois os estudos que tratam das habilidades sintáticas e os que investigam ambas, ou seja, as habilidades morfossintáticas.

Em vários estudos, o desenvolvimento de habilidades para manipulação de conhecimento morfológico encontra-se associado aos indicadores de proficiência em língua escrita, principalmente, nos momentos mais avançados do processo de sua aprendizagem, quando o aprendiz já teria automatizado o reconhecimento e uso das relações grafo-fonológicas, podendo ocupar-se das dimensões de sentido da língua. Nesta perspectiva, em estudo com crianças norte-americanas de 8 a 12 anos, em séries que correspondem da $3^{\mathrm{a}}$ à $6^{\mathrm{a}}$ série, Mann e Singson (2003) identificaram que o conhecimento sobre morfologia derivacional de sufixos tem um importante papel na decodificação de palavras derivadas, fonologicamente opacas ${ }^{4}$ e de palavras como morfema lexical de baixa frequência.

É importante salientar que estudos anteriores já tinham evidenciado a importância da análise morfológica para a construção do significado de palavras derivadas, não familiares e morfologicamente complexas (NAGY; ANDERSON, 1984; TYLER; NAGY, 1989). Além do mais, Carlisle e Fleming (2003) relatam que o conhecimento sobre aspectos semânticos e sintáticos dos morfemas

4 Palavras cuja grafia correta não é produzida pela aplicação exclusiva do princípio biunívoco de correspondência entre grafemas e fonemas. 
auxilia o processamento de sentenças e a compreensão em leitura, nos anos mais avançados do ensino fundamental.

No entanto, alguns estudos recentes têm chamado a atenção para a manifestação implícita do conhecimento morfológico ${ }^{5}$ em crianças que estão no processo inicial de alfabetização. Esses destacam que o reconhecimento de palavras, mesmo no início da alfabetização, não se restringe aos fatores relacionados à decodificação grafo-fonológica. Em outras palavras, há evidências de que o reconhecimento de palavras é tributário da contribuição de múltiplos fatores, dentre eles a análise dos componentes morfológicos da palavra. (COLÉ; MAREC-BRETON; ROYER; GOMBERT, 2003; MAREC-BRETON, 2003). Focalizando a aprendizagem da escrita em francês, os autores citados argumentam que a análise dos componentes morfológicos auxilia o reconhecimento de palavras desde o início do processo de alfabetização, que ocorre por volta dos seis anos de idade.

Estudos sobre o papel da consciência morfológica na aquisição inicial do inglês também ressaltam a importância de se considerar o papel deste tipo de habilidade para ler palavras morfologicamente complexas, bem como para o reconhecimento de morfemas lexicais e afixos. (CARLISLE, 2003; CARLISLE; FLEMING, 2003). O mesmo é referendado para a língua italiana (BURANI; MARCOLINI; STELLA, 2002) e confirmado por novos estudos realizados sobre a língua francesa (MAREC-BRETON; GOMBERT; COLÉ, 2005).

Um dos primeiros estudos longitudinais que teve como propósito investigar as relações entre desenvolvimento da consciência morfológica, da consciência fonológica e da leitura, foi realizado por Carlisle (1995) com crianças de língua inglesa, da educação infantil ( 3 e 4 anos) à primeira e à segunda série do ensino fundamental ( 7 e 8 anos). Para verificar consciência morfológica, utilizou uma tarefa de produção morfológica (ex.: Farm. My uncle is a __. Resposta esperada: farmer) e outra de julgamento morfológico (ex.: Você acha que a palavra fabulous vem da palavra fable?). Para consciência fonológica, um teste exigia a produção de uma nova palavra com a subtração de um elemento específico (ex.: Fale meat. Agora repita, mas sem falar o /m/). Para avaliar leitura,

5 Conhecimento implícito é aquele que se instala naturalmente, sem esforço, durante o desenvolvimento linguístico da criança, mas não é elaborado para expressão verbal e para o controle deliberado. É um conhecimento usado de modo intuitivo, não consciente. O conhecimento explícito, de outra parte, é aquele que pode ser expresso verbalmente, sobre o qual a pessoa pode refletir, manipular e reelaborar intencionalmente. A aprendizagem implícita de conhecimentos linguísticos requer o contato frequente e regular com a língua, já a aprendizagem explícita, exige, além disso, o engajamento da atenção consciente para a representação e expressão verbal do objeto de conhecimento, tal como é típico das práticas de alfabetização no contexto da educação formal (Gombert, 2005; Leme, 2008; Paula; Leme, no prelo). 
utilizou uma tarefa de compreensão (marcar a resposta correta para questões sobre passagens curtas ou completar sentenças, escolhendo a melhor resposta) e outra de análise fonética (marcar uma dentre quatro opções de palavras, a que contém um som especificado). Os resultados do estudo mostram uma ampliação significativa da consciência morfológica da educação infantil à $1^{\mathrm{a}}$ série; que os desempenhos nas tarefas de consciência morfológica e de consciência fonológica nas crianças de $1^{\mathrm{a}}$ série explicam uma porção significativa da variância nos testes de leitura (análise da palavra e compreensão) na $2^{\mathrm{a}}$ série; e que a consciência morfológica oferece uma contribuição independente para predizer o desempenho na tarefa de compreensão de leitura na segunda série.

Entretanto, em estudo no qual testaram hipóteses sobre as relações entre morfologia e fonologia no início da aprendizagem da leitura, Laxon, Rickard e Coltheart (1992) tinham mostrado que leitores iniciantes fazem uso da estrutura morfológica para a leitura de palavras, mas que esta utilização é dependente do emprego de regras fonológicas. Esta aparente discrepância nos resultados dos dois estudos descritos traz à tona a questão colocada por Fowler e Liberman (1995) e Bowey (2005), a consciência morfológica não contribui de forma independente para a alfabetização, mas é um subproduto do processamento fonológico.

Nesse sentido, as pesquisadoras Fowler e Libermam (1995) investigaram as possíveis interdependências entre conhecimento morfológico, fonológico e ortográfico em crianças de sete anos e meio a nove anos e meio, que foram agrupadas em função da avaliação do nível de leitura e de vocabulário, em cada idade. Um aspecto a ser destacado dos experimentos relatados nesse estudo foi a utilização de uma tarefa de produção morfológica modelada por Annete Carlisle em estudos anteriores, que permitia examinar o papel da complexidade fonológica, envolvendo sufixos apresentados com a base, ora em palavras em que esta era fonologicamente deformada pelo sufixo (PhonComplex - ex.: fivel fifth) ora, com integridade fonológica da base mantida (PhonNeutral - ex.: four/ fourth). Seus resultados mostram fortes correlações entre habilidades de leitura e soletração e desempenho na tarefa morfológica. Contudo, as autoras identificaram menor desempenho na utilização do conhecimento morfológico nos itens PhonComplex, aparentemente por deficiências no conhecimento fonológico, identificadas em leitores fracos.

Em estudo mais recente Colé, Royer, Leuwers e Casalis (2004) investigaram alunos da classe de alfabetização até a segunda série ${ }^{6}$. Eles verificaram que o desempenho em leitura está relacionado ao desenvolvimento do conhecimento morfológico implícito desde a classe de alfabetização, mas que,

$6 \mathrm{O}$ que corresponderia aos três primeiros anos do atual Ensino Fundamental brasileiro de nove anos. 
a partir do que corresponde à $1^{\mathrm{a}}$ série, o desempenho em leitura passa a ser influenciado também por conhecimentos morfológicos explícitos. Em virtude desses resultados, os autores defendem a integração da influência de conhecimentos tanto implícitos quanto explícitos sobre morfologia em modelos da aprendizagem da leitura, desde o início da alfabetização. Ademais, análises de regressão em diversos estudos transversais confirmam que, pelo menos a partir da $1^{\mathrm{a}}$ série, os conhecimentos morfológicos desempenham papel importante em tarefas de leitura independente do nível de vocabulário (MANN; SINGSON, 2003).

Acrescenta-se que, além dos estudos que examinaram as relações entre competência morfológica e aquisição da leitura, também foram encontrados na literatura estrangeira estudos que examinam as relações entre competência morfológica e aprendizagem da ortografia. Dentre os estudos que exploraram esta relação, despontam os de Pacton (2003), a respeito da língua inglesa, Pacton, Fayol e Perruchet (2002) e Rocher (2005) para o francês.

Estudos comparativos entre línguas destacam que, dadas as peculiaridades dos diferentes sistemas de escrita, a morfologia tem importância e papel variáveis para a aquisição da leitura e da escrita (GOMBERT, 2009).

De outra parte, identifica-se também um conjunto de estudos que apoiam a ideia de que a consciência sintática contribui para a aquisição da leitura e da escrita.

Um dos primeiros estudos que forneceu sustentação a essa ideia foi realizado por Guthrie (1973). Ele comparou um grupo de crianças de 10 anos de idade com dificuldades de leitura com um grupo de crianças de sete anos de idade; ambos os grupos apresentavam nível de leitura equivalente a sete anos de idade. $\mathrm{O}$ referido pesquisador constatou que as crianças mais novas, que apresentavam nível de leitura adequado para a sua idade, tiveram um desempenho significativamente melhor do que as crianças mais velhas, em uma tarefa de leitura, na qual as crianças eram solicitadas a escolher, a cada cinco palavras (aproximadamente), qual dentre três palavras alternativas seria a palavra correta a inserir naquele ponto no texto. Vale notar que o significado de algumas das palavras alternativas não combinava com o texto, embora fossem de classe gramatical apropriada. Outras não podiam ser inseridas no texto, por apresentarem significado e classe gramatical impróprios. Os dados obtidos nesse estudo levaram Guthrie (1973) a concluir que as crianças com dificuldades de leitura têm menor habilidade que as outras crianças para utilizar pistas gramaticais na leitura.

Outro estudo, realizado por Tunmer, Nesdale e Wright (1987), comparou crianças mais jovens (bons leitores), do mesmo nível de leitura de crianças mais velhas (maus leitores), em diversas tarefas, sendo duas delas de consciência sintática (completar oralmente as palavras ausentes nas sentenças e corrigir 
sentenças gramaticalmente incorretas, porque as palavras estavam na ordem errada). Os resultados indicaram que as crianças mais jovens, os bons leitores, saíram-se melhor nas tarefas de consciência sintática do que as crianças mais velhas, os maus leitores. Para Tunmer et al., esse resultado constitui evidência de que o atraso no desenvolvimento da consciência sintática pode retardar o desenvolvimento da capacidade de leitura, sugerindo que a consciência sintática pode estar relacionada com as dificuldades (diferenças) na aprendizagem da leitura. Nessa perspectiva, eles formularam a hipótese de que a aprendizagem inicial da leitura é influenciada tanto pela consciência fonológica quanto pela consciência sintática.

Para testar essa hipótese, Tunmer, Herriman e Nesdale (1988) conduziram um estudo com 100 crianças australianas, nas quais foram administradas uma tarefa de consciência sintática (corrigir sentenças incorretas) e uma tarefa de consciência fonológica (contar os fonemas de palavras sem sentido). Por meio desse estudo, os pesquisadores constataram uma relação preditiva entre esses dois aspectos da consciência metalinguística (consciência sintática e consciência fonológica) e o desenvolvimento da capacidade da criança na decodificação e compreensão da leitura.

Em estudo posterior, Tunmer (1990) verificou que as crianças utilizam seus conhecimentos sintáticos para dissimular o fracasso da análise fonológica de palavras não familiares (por exemplo, "boxe") ou de palavras homógrafas (por exemplo, "sede" com suas duas pronúncias).

$\mathrm{Na}$ realidade, vários estudos realizados na língua inglesa defendem a importância da consideração dos aspectos morfossintáticos para a produção de grafias, entre eles destaca-se o que foi realizado por Nunes, Bryant e Bindman (1995), que investigaram crianças inglesas na faixa etária de 6 a 11 anos quanto aos processos envolvidos no aperfeiçoamento da ortografia após a primeira série. De acordo com esses autores, seus resultados indicam a possibilidade de que a tomada de consciência de aspectos morfossintáticos da língua constitua uma explicação para o desenvolvimento ortográfico.

\section{Consciência morfossintática e a aprendizagem da leitura} e da escrita: estudos realizados no Brasil

O português é uma língua alfabética mais transparente do que outras línguas alfabéticas (como o inglês, por exemplo), ou seja, apresenta maior grau de correspondência entre letras e sons da fala, o que sugere uma contribuição menos significativa das habilidades morfológicas e sintáticas na aquisição da linguagem escrita. Contudo, na última década, vários estudos em Língua 
Portuguesa têm apresentado evidências de relações entre a consciência morfossintática e o desempenho na modalidade escrita.

Os primeiros estudos que investigaram essas relações concentraram-se especificamente em consciência sintática, sendo seus resultados aparentemente discrepantes. Este é o caso dos estudos de Rego $(1993,1995)$ que investigou dois grupos de crianças brasileiras. No primeiro, em que participaram 32 crianças que frequentavam uma escola de orientação construtivista, Rego (1993) verificou que a consciência sintática constitui um bom preditor do progresso das crianças tanto na decodificação quanto na compreensão da leitura. Entretanto, em outro estudo, em que participaram 50 crianças alfabetizadas por meio de um método tradicional com ênfase exclusiva no ensino de padrões silábicos, Rego (1995) encontrou resultados diferentes, ou seja, não constatou uma conexão entre consciência sintática e progresso inicial em decodificação.

Instigados por essa discrepância de resultados, Rego e Buarque (1997) realizaram uma investigação com 46 crianças em que avaliaram a relação entre o desenvolvimento da consciência metalinguística (consciência fonológica e sintática) no início da $1^{\mathrm{a}}$ série e o desempenho em ortografia no final da $1^{\mathrm{a}}$ e $2^{\mathrm{a}}$ séries. Seus resultados mostram que a consciência fonológica está relacionada com a aquisição de regras que dependem da análise do contexto grafo-fônico (por exemplo: o som /g/ como em "gato" quando ocorre diante de /e/ e /i/ é representado pelo dígrafo "gu" como em "guerra"), enquanto a consciência sintática é um facilitador específico da aquisição de regras que envolvem a utilização de critérios gramaticais (por exemplo: o ditongo /iw/ é sempre grafado com "iu" no verbo como em "fugiu", podendo ser "io" e "il" nos substantivos como em "navio" e "barril").

Poucos anos depois, Guimarães (2001) realizou um estudo com bons e maus leitores, com o objetivo de investigar a relação entre o nível das habilidades fonológicas e sintáticas/morfossintáticas (as tarefas envolviam aspectos morfossintáticos) e o desempenho na leitura e escrita de palavras isoladas. Participaram da investigação três grupos de crianças: 20 alunos com dificuldades em leitura e escrita, cursando $3^{\mathrm{a}}$ e $4^{\mathrm{a}}$ séries (grupo 1); 20 alunos da $1^{\mathrm{a}}$ série, com o mesmo nível de leitura e escrita dos participantes do grupo 1 (grupo 2) e 20 alunos da $3^{\mathrm{a}}$ e $4^{\mathrm{a}}$ séries, com a mesma idade cronológica dos participantes do grupo 1 (grupo 3). Comparações feitas entre o desempenho das crianças com dificuldades de aprendizagem da leitura e da escrita, com o grupo de crianças mais novas mostraram um déficit no processamento fonológico das crianças com dificuldades de aprendizagem, mas nenhuma diferença estatisticamente significativa nas tarefas de sintaxe/morfossintaxe. Além disso, os grupos 1 e 2 mostraram um desempenho nas tarefas de consciência sintática significativamente inferior ao do grupo 3, sugerindo que o desenvolvimento da habili- 
dade sintática está relacionado com a maior experiência em leitura e escrita. A autora sugere que os problemas no processamento fonológico dos alunos do grupo 1 podem ter impedido que eles fossem beneficiados pelas experiências em leitura e em escrita, como aconteceu com os outros alunos da mesma idade cronológica e, por isso, embora com mais tempo de escolaridade, permaneceram com o mesmo nível de consciência sintática que os participantes do grupo 2, que eram mais inexperientes. Essa hipótese também foi levantada por Bowey (2005) e permanece como uma das principais questões a ser investigada em estudos futuros.

Neste contexto teórico, Diniz (2008) procedeu a uma investigação da influência de um programa de intervenção, baseado em atividades voltadas para o desenvolvimento de habilidades metafonológicas e metassintáticas, sobre o incremento do domínio em leitura e escrita. O estudo teve um delineamento experimental e foi desenvolvido com dois grupos (experimental e controle), em três fases: pré-teste, intervenção (apenas no grupo experimental) e pós-teste. Os resultados mostraram que apenas no grupo experimental houve diferenças significativas na comparação das médias pré e pós-teste para tarefas de avaliação das habilidades fonológicas e escrita de palavras. Nas tarefas de avaliação das habilidades sintáticas e leitura ambos os grupos progrediram significativamente. Aparentemente, esses resultados sugerem que, independentemente de um treinamento extracurricular, o aumento das experiências com a língua escrita, propiciadas pelas atividades de leitura e escrita dos escolares, possibilita um desenvolvimento paralelo das habilidades sintáticas e de leitura. Contudo, esses resultados devem ser analisados com cuidado, avaliando-se também os instrumentos utilizados. Acredita-se que são necessários novos estudos que utilizem diferentes tarefas e em outras amostras para se chegar a conclusões sobre essa questão.

De outra parte, diferentes estudos realizados em português do Brasil têm encontrado evidências de uma relação entre a consciência morfológica e o desempenho na leitura e na escrita. Estas relações devem-se ao fato de que, embora o português seja uma língua mais regular do que o inglês, há muitas ocasiões em que a morfologia pode auxiliar na escolha da grafia correta das palavras (MEIRELES; CORREA, 2005; MEIRELES; CORREA, 2006; PAULA, 2007; MOTA, 2008). Este é o caso da sequência sonora /eza/, este sufixo é escrito como "esa" quando formador de femininos (p. ex.: japonesa, camponesa etc.), enquanto o sufixo "eza" é formador de substantivos abstratos (p. ex.: beleza, nobreza etc.).

Paula (2007), com o objetivo de estudar conhecimentos implícitos e explícitos sobre a dimensão morfológica, derivacional e flexional, investigou dois grupos de crianças brasileiras de ambos os sexos, sendo 50 dos primeiros anos escolares ( $1^{\mathrm{a}}$ e $3^{\mathrm{a}}$ séries $)$ e 210 de anos escolares mais avançados $\left(5^{\mathrm{a}}\right.$ e $7^{\mathrm{a}}$ 
séries). A autora analisou também a relação do conhecimento morfológico sobre a aquisição da leitura (decodificação e compreensão) e da escrita (ortografia). Seus resultados sugerem que as crianças de $1^{a}$ série possuem conhecimentos implícitos (sensibilidade) em morfologia derivacional, principalmente sufixos; e a partir da $3^{a}$ série, eles demonstraram um número crescente de correlações entre conhecimento morfológico e desempenho em leitura e em escrita.

Nessa mesma perspectiva, Mota, Aníbal e Lima (2008) realizaram uma investigação com vistas a verificar a contribuição do processamento da morfologia derivacional para a leitura e a escrita no português, analisando também se essa contribuição é dependente da consciência fonológica, ou seja, subproduto do processamento fonológico. Seus resultados mostram que a habilidade de refletir sobre os morfemas contribui tanto para a leitura como para a escrita, sendo essa contribuição até certo ponto independente do processamento fonológico.

Salienta-se, outrossim, que dois anos antes Queiroga, Lins e Pereira (2006) haviam realizado uma pesquisa envolvendo 120 alunos de $2^{\mathrm{a}}$ e $4^{\mathrm{a}}$ séries de escolas públicas e particulares, na qual investigaram a relação entre a consciência morfossintática e o desempenho ortográfico. Seus resultados mostraram um efeito preditor do conhecimento morfossintático sobre o desempenho ortográfico, bem como uma evolução entre as séries na explicitação do conhecimento morfossintático e na escrita de palavras e pseudopalavras.

\section{Considerações sobre os estudos revisados e agenda futura}

A revisão de estudos sobre a habilidade morfossintática e sua relação com a aprendizagem da linguagem escrita revela o caráter multidimensional desta habilidade, cujas dimensões podem requerer níveis diferentes de processamento e apresentar valor preditivo diverso na aquisição da leitura e escrita. Por exemplo, examinando os efeitos do conhecimento de sufixos sobre a escrita, Deacon e Bryant (2005) verificaram que crianças de 5 a 8 anos demonstraram ter consciência das flexões, mas não das derivações. Ao analisar seus resultados, os autores concluem que é mais difícil para as crianças entender as relações morfêmicas nas derivações do que nas flexões devido ao fato de que na morfologia derivacional há uma mudança na classe gramatical das palavras morfologicamente complexas, o que não ocorre na morfologia flexional.

O português é uma língua cujo grau de regularidade de correspondência entre letras e sons é bem maior do que o inglês, mas ele não obedece estrita- 
mente o princípio alfabético. Conforme foi apresentado na seção anterior, vários estudos têm verificado relações significativas entre o desempenho em tarefas que avaliam habilidades morfossintáticas e o desempenho em leitura e escrita do português. Entretanto, uma das grandes dificuldades apontadas nesses estudos diz respeito à capacidade de os instrumentos (tarefas morfossintáticas) utilizados terem acesso ao caráter reflexivo e intencional da criança.

Na realidade, a quantidade de estudos envolvendo a consciência morfossintática e suas relações com a aprendizagem da leitura e escrita em português é ainda muito pequena. A agenda nacional de pesquisas sobre este tema é extensa e necessária, pois estas investigações deverão trazer novas e mais completas explicações acerca da origem, do padrão de desenvolvimento, da estrutura, das formas de mensuração e influência das habilidades morfossintáticas para a aquisição da linguagem escrita.

Em síntese, dada a complexidade que reveste o tema do desenvolvimento das habilidades morfossintáticas, enfatiza-se a necessidade de novos estudos, sobretudo estudos longitudinais que possam estabelecer uma possível conexão causal entre essa habilidade metalinguística, o domínio nos níveis implícito e explícito do conhecimento morfossintático e a aquisição e aperfeiçoamento da leitura e escrita. Esse tipo de estudo é necessário para explorar melhor como e quando é desenvolvida a consciência morfossintática, ou seja, os níveis de progressão do processamento das informações morfossintática. E, mais do que isso, enfatiza-se a necessidade de estudos de intervenção que possibilitem verificar como o ensino dessa habilidade pode auxiliar os alunos a utilizarem de forma intencional e deliberada o conhecimento dos aspectos morfossintáticos como estratégia de leitura e de escrita.

\section{REFERÊNCIAS}

BARRERA, S. D.; MALUF, M. R. Consciência metalinguística e alfabetização: um estudo com crianças da primeira série do ensino fundamental. Psicologia: reflexão e crítica, v. 16, n. 3, p. 491- 502, 2003.

BOWEY, J. Grammatical sensitivity: its origins and potential contribution to early reading skill. Journal of Experimental Child psychology, v. 90, p. 318-343, 2005. 
BRADLEY, L.; BRYANT, P. E. Categorizing sounds and learning to read - a causal connection. Nature, v. 301, p. 419-421, 1983.

BURANI, C., MARCOLINI, S., \& STELLA, G. How early does morpho-lexical reading develop in readers of a shallow orthography? Brain and Language, v. 81 , p. 568-586, 2002.

CAPOVILLA, A. G. S.; CAPOVILLA, F. C. Efeitos do treino de consciência fonológica em crianças com baixo nível sócio-econômico. Psicologia: reflexão e crítica, v. 13, n. 1, p. 7-24, 2000.

CARDOSO-MARTINS, C. Sensitivity to rhymes, syllables, and phonemes in literacy acquisition in Portuguese. Reading Research Quarterly, v. 30, n. 4, p. 808-827, 1995.

CARLISLE, J. Awareness of the structure and meaning of morphologically complex words: impact on reading. Reading and Writing: An Interdisciplinary Journal, v. 12, p. 169-190, 2000.

CARLISLE, J. F. Morphological awareness and early reading achievement. In: FELDMAN, L. B. (Ed.). Morphological aspects of language processing. Hillsdale, New Jersey: Lawrence Erlbaum Associates, 1995. p. 189-209.

CARLISLE, J. F. Morphology matters in learning to read: A commentary. Reading Psychology, v. 24, p. 373-404, 2003.

CARLISLE, J.F.; FLEMING, J. Lexical processing of morphologically complex words in elementary years. Scientific Studies of Reading, v. 7, n. 3, p. 239-253, 2003 .

CARONE, F. B. Morfossintaxe. 9.ed. São Paulo: Ática, 2006.

COLÉ, P.; MAREC-BRETON, N. ; ROYER, C. ; GOMBERT, J. Morphologie des mots et apprentissage de la lecture. Reeducation Orthophonic, v. 213, p. 57-60, 2003.

COLÉ, P. ; ROYER, C. ; LEUWERS, C. ; CASALIS, S. Les connaissances orphologiques dérivationnelles et l'apprentissage de la lecture chez l'apprentilecteur français du C.P. au C.E.2. L'Année Psychologique, v. 104, p. 701-750, 2004. 
DEACON, S. H.; BRYANT, P. What young children do and do not know about the spelling of inflections and derivations. Developmental Science, v. 8, n. 6, p. 583-594, 2005.

DINIZ, N. L. B. Metalinguagem e alfabetização: efeitos de uma intervenção para recuperação de alunos com dificuldades na aprendizagem da linguagem escrita. São Paulo, 2008. 260p. Tese (Doutorado) - Instituto de Psicologia, Universidade de São Paulo.

FOWLER, A.; LIBERMAN, I. The role of phonology and orthography in morphological awareness. In: FELDMAN, L. (Org.). Morphological aspects of language processing Hillsdale: Lawrence Erlbaum Associates, 1995. p. 157-188.

GOMBERT, J. E. Metalinguistic development. Hertfordshire: Harvester Wheatsheaf, 1992.

GOMBERT, J-E. Est si l'automatisation n'existait pas ? L'implicite et l'explicite dans l'aprrentissage de l'écrit et ses troubles. Revue Parole, v. 34-35-36, p. 245-263, 2005.

GOMBERT, J. E. Preface. In: MAREC-BRETON, N.; BESSE, A. S.; HAYE, F. de la; BONNETON-BOTTÉ, N.; BONJOUR, E. (Orgs.). L'apprentissage de la langue écrite. Rennes: Presses Universitaires de Rennes (PUR), 2009.

GUIMARÃES, S. R. K. Dificuldades no desenvolvimento da lectoescrita: o papel das habilidades metalinguísticas. Psicologia: Teoria e Pesquisa, v. 19, n. 1, p. 33-45, 2003.

GUIMARÃES, S. R. K. Dificuldades na aquisição e aperfeiçoamento da leitura e da escrita: o papel da consciência fonológica e da consciência sintática. 269p. Tese (Doutorado) - Instituto de Psicologia, Universidade de São Paulo. São Paulo, 2001.

GUTHRIE, J.T. Reading comprehension and syntactic responses in good and poor readers. Journal of Educational Psychology, v. 65, n. 3, p. 294-299, 1973.

KATO, M. A. O aprendizado da leitura. 5. ed. São Paulo: Martins Fontes, 1999.

LANDSMANN, L. T. Aprendizagem da linguagem escrita. São Paulo: Ática, 1998. 
LAROCA, M. N. C. Manual de Morfologia do Português. Campinas: Pontes Editores, 2005.

LAXON, V.; RICKARD, M.; COLTHEART, V. Children read affixed words and non-words. British Journal of Psychology, v. 83, p. 407-423, 1992.

LEME, M. I. S. Reconciliando divergências: conhecimento implícito e explícito na aprendizagem. Psicologia USP, v. 19, n. 2, p. 121-127, 2008.

MANN, V.; SINGSON, M. Linking morphological knowledge to English decoding ability: Large effects of little suffixes. In: ASSINK, E.; SANDRA, D. (Eds.). Morphology and reading. Amsterdam: Kluwer Publishers, 2003. p. 1-25.

MAREC-BRETON, N. Les traitemant morphologiques dans l'apprentissage de la lecture. Tese (Doutorado) - Université de Rennes 2, Rennes, 2003.

MAREC-BRETON, N.; GOMBERT, J. E. A dimensão morfológica nos principais modelos de aprendizagem da leitura. In: MALUF, M. R. (Org.). Psicologia educacional: questões contemporâneas. São Paulo: Casa do Psicólogo, 2004. p. 105-121.

MAREC-BRETON, N. ; GOMBERT, J. E. ; COLÉ, P. Traitements morphologiques lors de la reconnaissance des mots ecrits chez des apprentis lecteurs. L'année psychologique, v. 105, n.1, p. 9-45, 2005.

MOTA, M. M. P. E. Considerações sobre o papel da consciência morfológica nas dificuldades de leitura e escrita: uma revisão da literatura. Revista Semestral da Associação Brasileira de Psicologia Escolar e Educacional, v. 12, n. 2, p. 347-355, 2008.

MOTA, M. Introdução - Desenvolvimento metalinguístico. In: MOTA, M. (Org.). Desenvolvimento metalinguístico: questões contemporâneas. São Paulo: Casa do Psicólogo, 2009. p. 9-18.

MOTA, M. M. P. E.; ANIBAL, L.; LIMA, S. A Morfologia Derivacional Contribui para a Leitura e Escrita no Português? Psicologia: Reflexão e Crítica, v. 21, n. 2, p. 311-318, 2008.

NAGY, W. E.; ANDERSON, R. C. How many words are there in printed school English? Reading Research Quarterly, v. 19, n. 3, p. 304-330, 1984. 
NUNES, T.; BRYANT, P.; BINDMAN, M. E quem se preocupa com a ortografia? In: CARDOSO-MARTINS, C. (Org.). Consciência fonológica \& Alfabetização. Petrópolis: Vozes, 1996. Cap.5, p.129-158.

PACTON, S. Morphologie et acquisition de l'orthographe: état dês recherches actuelles. Rééducation Orthophonique, v. 213, p. 27-55, 2003.

PACTON, S. ; FAYOL, M. ; PERRUCHET, P. Acquérir l'orthographe du Français: Apprentissages implicite et explicite. In: FLORIN, A.; MORAIS, J. (Eds.). La maïtrise du langage. Rennes: Presses Universitaires de Rennes, 2002. p. 95-118.

PLAZA, M.; COHEN, H. Predictive influence of phonological processing, morphological/syntactic skill, and naming speed on spelling performance. Brain and Cognition, v. 55, p. 368-373, 2004.

PLAZA, M.; COHEN, H. The interaction between phonological processing, syntactic awareness, and naming speed in the reading and spelling performance of first-grade children. Brain and Cognition, v. 53, p. 257-292, 2003.

PAULA, F. V. Conhecimento morfológico implícito e explícito na linguagem escrita. 200p. Tese (Doutorado em Cotutela) - Instituto de Psicologia, Universidade de São Paulo, São Paulo \& Université de Rennes 2, Rennes, França, 2007.

PAULA, F. V.; LEME, M. I.S. O Paradigma da aprendizagem implícita e explícita: uma visão integradora das formas de aprender. Psicologia em Estudo, no prelo.

QUEIROGA, B. A. M.; LINS, M. B.; PEREIRA, M. A. L. V. Conhecimento Morfossintático e Ortografia em Crianças do Ensino Fundamental. Psicologia: Teoria e Pesquisa, v. 22, n. 1, p. 95-100, 2006.

REGO, L.L.B. O papel da consciência sintática na aquisição da língua escrita. Temas em Psicologia, v. 1, p. 79-87, 1993.

REGO, L.L.B. Diferenças individuais na aprendizagem inicial da leitura : Papel desempenhado por fatores metalingüísticos. Psicologia: Teoria e Pesquisa, v. 11, n. 1, p. 51-60, 1995.

REGO, L. L. B.; BRYANT, P. E. The connection between phonological syntactic and semantic skills and children's reading and spelling. European Journal of Psychology of Education, v. 8, n. 3, p. 235-246, 1993. 
REGO, L. L. B.; BUARQUE, L. L. Consciência sintática, consciência fonológica e a aquisição de regras ortográficas. Psicologia Reflexão e Crítica, v. 10, p. 199-217, 1997.

ROAZZI, A.; ASFORA R.; QUEIROGA, B. Consciência morfossintática: novas explorações. In: GUIMARÃES, S. R. K.; MALUF, M. R. (Orgs.). Aprendizagem da Linguagem Escrita. Contribuições de pesquisas. São Paulo: Vetor, no prelo.

ROAZZI, A.; DOWKER, A. Consciência fonológica, rima e aprendizagem da leitura. Psicologia: Teoria e Pesquisa, v. 5, p. 31-55, 1989.

ROCHA, L. C. A. Estruturas morfológicas do português. 2.ed. São Paulo: Editora WMF Martins Fontes, 2008.

ROCHER, A. S. Regularities graphophonologiques, orthographiques et orphologiques: appresntissage implicite et impact precoce sur la lecture.. Tese (Doutorado) - Université de Rennes 2, Rennes, 2005.

SANDMANN, A. J. Morfologia lexical. São Paulo: Contexto,1992.

SILVA, M.C.P.S.; KOCH, I.G.V. Linguística aplicada ao português: morfologia. São Paulo: Cortez, 2005.

TUNMER, W. E. The role of language prediction skills in beginning reading. New Zealand Journal of Educational Studies, v. 25, n. 2, p. 95-114, 1990.

TUNMER, W. E.; HERRIMAN, M. L.; NESDALE, A. R. Metalinguistic abilities and beginning reading. Reading Research Quartely, v. 23, n. 2, p. 134-158, 1988.

TUNMER, W.E.; NESDALE, A.R.; WRIGHT, A.D. Syntactic awareness and reading acquisition. British Journal of Developmental Psychology, Great Britain, v. 5, p. 25-34, 1987.

TYLER, A.; NAGY, W. The acquisition of English derivational morphology. Journal of Memory and Language. v. 28, p. 649-667, 1989.

Texto recebido em 2 de junho de 2010.

Texto aprovado em 30 de junho de 2010. 